\title{
Cervical Instability as a Cause of Barré-Liéou Syndrome and Definitive Treatment with Prolotherapy: A Case Series
}

\author{
Ross A. Hauser ${ }^{1}$, Danielle Steilen ${ }^{1}$, Ingrid Schaefer Sprague ${ }^{2}$ \\ ${ }^{1}$ Caring Medical and Rehabilitation Services, Oak Park, IL, USA \\ ${ }^{2}$ ImageWrite Media, Cleveland, OH, USA
}

Email address:

drhauser@caringmedical.com (R. A. Hauser), steilend@caringmedical.com (D. Steilen), ingridsprague@gmail.com (I. S. Sprague)

\section{To cite this article:}

Ross A. Hauser, Danielle Steilen, Ingrid Schaefer Sprague. Cervical Instability as a Cause of Barré-Liéou Syndrome and Definitive Treatment with Prolotherapy: A Case Series. European Journal of Preventive Medicine. Vol. 3, No. 5, 2015, pp. 155-166.

doi: $10.11648 /$ j.ejpm. 20150305.15

\begin{abstract}
Barré-Liéou syndrome, or posterior cervical sympathetic syndrome, has symptomatology related to underlying cervical instability. While classified as a rare disease, Barré-Liéou syndrome is likely underdiagnosed. Vertebral instability, occurring after neck ligament injury, affects the function of cervical sympathetic ganglia (located anterior to vertebral bodies). Symptomatology includes neck pain, migraines/headache, vertigo, tinnitus, dizziness, visual/auditory disturbances, and other symptoms of the head/neck region. Treatment for Barré-Liéou syndrome is suboptimal and often involves long-term use of pain medications, chiropractic care, or surgical fusion. Prolotherapy offers a noninvasive treatment option to ameliorate symptoms while treating the underlying cause of the disorder - cervical instability. In this case series, the results of eight patients from 2011 to 2013 who received prolotherapy for Barré-Liéou syndrome following longstanding symptoms after trauma are reported. All patients reported improvement of neck pain and associated symptoms and increased physical activity. Prolotherapy should be considered as treatment for Barré-Liéou syndrome.
\end{abstract}

Keywords: Barré-Liéou Syndrome, Cervical Instability, Cervical Spondylosis, Posterior Cervical Sympathetic Syndrome, Prolotherapy

\section{Introduction}

Barré-Liéou syndrome presents a unique challenge to the clinician since its diagnosis is under-recognized and definitive treatment of the condition requires elucidation. Although data indicate Barré-Liéou syndrome affects less than 200,000 patients in the U.S., this may be more the result of fewer cases being correctly diagnosed rather than the frequency of the disease itself [1]. Barré-Liéou syndrome is a syndrome of the cervical sympathetic nerves and ganglia that includes the common symptoms of headaches, dizziness, vertigo, and auditory and visual manifestations - which are frequently attributed to the diagnosis of migraine headache. It is curious to consider Barré-Liéou syndrome, or posterior cervical sympathetic syndrome, as the etiology of these common symptoms, as they are often considered idiopathic with no known cause. However, the incidence of each specific symptom has been reported across patient populations and indicates a chronic problem. On average 5\% to $10 \%$ of the general population experiences dizziness and vertigo, and this symptom can affect up to $40 \%$ of those who are over 40 years of age [2]. Approximately $16.2 \%$ to $22.7 \%$ of adults in the U.S. suffer from migraine headaches, and there appears to be some overlap of both migraines and vertigo in some of these patients [3, 4]. Lastly, $10 \%$ to $15 \%$ of this population experiences tinnitus [4]. As there are no strict criteria for the diagnosis of Barré-Liéou syndrome and its related symptoms can be observed in the general population, this syndrome may actually be more common than previously thought despite its low rate of diagnosis.

Barré-Liéou syndrome is thought to be caused by a disruption of sympathetic nerve function by structural deformation of the cervical spine. Other symptoms can include laryngeal disturbances known as "oscillating aphonia" as well as neck muscle cramps and psychoneurotic manifestations, typically insomnia, anxiety, and depression. Symptoms that characterize Barré-Liéou syndrome also include facial pain or numbness, ear pain, tinnitus, hoarseness, severe fatigue, muscle weakness, sinus congestion, a sense of eyeball extrusion, dysesthesias of the hands and forearms (pins-and-needles sensation), corneal 
sensitivity, dental pain, lacrimation, blurred vision, shoulder pain, unilateral swelling of the face, nausea, vomiting, and localized cyanosis of the face [6-8] (Figure 1).

\begin{tabular}{|c|c|c|c|c|c|}
\hline Symptoms & $\begin{array}{l}\text { Barré-Liéou } \\
\text { syndrome }\end{array}$ & $\begin{array}{c}\text { Post- } \\
\text { concussion } \\
\text { syndrome }\end{array}$ & $\begin{array}{l}\text { Whiplash } \\
\text { associated } \\
\text { disorder }\end{array}$ & $\begin{array}{l}\text { Atlanto-axial } \\
\text { instability }\end{array}$ & $\begin{array}{l}\text { Vertebrobasilar } \\
\text { insufficiency }\end{array}$ \\
\hline Neck pain/stiffness & $x$ & $x$ & $x$ & $x$ & $x$ \\
\hline Headache & $x$ & $x$ & $x$ & $x$ & $x$ \\
\hline Dizziness & $x$ & $x$ & $x$ & $x$ & $x$ \\
\hline Vertigo & $x$ & $x$ & $x$ & $x$ & $x$ \\
\hline Paresthesia (face) & $x$ & & & $x$ & $x$ \\
\hline Fatigue & $x$ & $x$ & $x$ & $x$ & $x$ \\
\hline Difficulty sleeping & $x$ & $x$ & $x$ & $x$ & $x$ \\
\hline Irritability & $x$ & $x$ & $x$ & $x$ & $x$ \\
\hline $\begin{array}{l}\text { Temporomandibular } \\
\text { joint dysfunction pain }\end{array}$ & & & $x$ & & \\
\hline Tinnitus & $x$ & $x$ & $x$ & $x$ & \\
\hline Nausea/vomiting & & $x$ & $x$ & $x$ & $x$ \\
\hline Visual disturbances & $x$ & $x$ & $x$ & $x$ & $x$ \\
\hline Cognitive impairment & $x$ & $x$ & $x$ & & \\
\hline Anxiety & $x$ & $x$ & $x$ & $x$ & $x$ \\
\hline Lightheadedness & $x$ & $x$ & $x$ & $x$ & $x$ \\
\hline Memory problems & $x$ & $x$ & $x$ & & \\
\hline Ear pain & $x$ & & & & \\
\hline Balance difficulty & & $x$ & $x$ & $x$ & $x$ \\
\hline Drop attacks & & & & $x$ & $x$ \\
\hline Dysphagia & & & & $x$ & $x$ \\
\hline Speech disturbances & & & & & $x$ \\
\hline Suboccipital headache & $x$ & $x$ & $x$ & $x$ & \\
\hline Cranial nerve symptoms & & & & & $x$ \\
\hline Sinus congestion & $x$ & & & & \\
\hline Eyeball pain & $x$ & & & & \\
\hline
\end{tabular}

Figure 1. A differential diagnosis of Barré-Liéou syndrome involves the comparison of symptoms of Barré-Liéou syndrome, post-concussion syndrome, whiplash, atlanto-axial instability, and vertebrobasilar insufficiency.

In the differential diagnosis these symptoms along with a complete history that includes neck trauma would indicate Barré-Liéou syndrome. However, Barré-Liéou syndrome can also result from neck ligament weakness and a sign of forward positioning of the head and neck without previous trauma [9-10]. This is referred to as "creep," the time-dependent elongation of a ligament under constant, low level stress. Barré-Liéou syndrome shares similar etiology with whiplash-associated disorder and post-concussion syndrome as a result of cervical instability (ligament injury) with an overlap of symptoms (Figure 1). When ligaments are injured from disease or trauma (either direct force or creep), resultant cervical instability and subsequent Barré-Liéou syndrome can occur.

\subsection{History of Barré-Liéou Syndrome}

In 1926, Barré reported on the connection between cephalic symptoms (headache and eye pain) and a distal cause, i.e. arthritis in the cervical spine. Barré first recognized the syndrome when he noted a group of symptoms characterized by vertigo and buzzing of the ears caused by lateral movements of the head in patients with cervical spine arthritis [5]. In 1928, Liéou independently described a similar syndrome presenting with headache, orbital pressure/pain, vertigo, and vasomotor disturbances. He proposed that these symptoms were related to alterations in the posterior cervical 
sympathetic chain and vertebral artery blood flow in patients with cervical spine arthritis and other related disorders [12]. The now-called Barré-Liéou syndrome is also known as posterior cervical syndrome or posterior cervical sympathetic syndrome, as the condition is presumed to be related to disruption of the posterior cervical sympathetic nervous system [11]. Barré and Liéou surmised that cervical arthritis or injury provoked an irritation of both the vertebral nerve and the sympathetic nerves, producing related symptoms.

Current treatment is centered on resolution of cervical instability and spondylosis and its effects on the posterior sympathetic nerves [5, 7, 12]. Etiology withstanding, the resultant cervical arthritis that causes irritation of the vertebral nerve and surrounding structures in turn allows for the manifestation of symptoms associated with Barré-Liéou syndrome.

\subsection{Connection Between Cervical Spine Instability and Ligament Injury with Barré-Liéou Syndrome}

Neck injury is highly correlated with Barré-Liéou syndrome. Trauma typically involves violent blows to the neck in automobile accidents, but also can be related to sports or chiropractic maneuvers [6], as well as slow stretching of the ligaments over time (e.g., poor posture over a computer or portable computer-screen devices, such as smartphones, eReaders, and computer tablets). In automobile accidents, neck sprain or strain is the most common type of injury as the forced hyperflexion and extension can cause ligamentous damage in the cervical spine. High-velocity manipulations by chiropractic adjustments of the cervical spine can additionally injure these ligaments, especially those of the upper cervical spine [13]. Both of these types of injuries can involve forces great enough to cause vertebral fractures or tears to ligaments, muscles or tendons in the neck. Ligamentous changes are also observed in patients who administer self-manipulation, as these repetitive movements can cause increased strain on cervical ligaments and subsequent cervical ligament laxity. Additionally, there have been case reports of dangerous events occurring after self-manipulation, including vertebral artery occlusion $[14,15]$. These types of serious adverse events occur more often after high-velocity chiropractic adjustments [16-20], as patients are more able to control their own neck motion during self-manipulation, reducing the risk of excess joint motion [21].

Changes in the sympathetic nervous system can be related to injury of the cervical nociceptors along with soft tissue injury. Barré-Liéou syndrome patients have hyperactive sympathetic responses, which are modifications to the normal firing patterns of the nerve endings. The specialized sensory neurons, known as nociceptors, of the injured ligaments respond to tissue damage; therefore, ligament injury to the cervical spine can also affect the sympathetic nervous system, as damage to these ligaments can alter nerve ending firing patterns. Nociceptors in injured ligaments and cervical facet joint capsules have a reduced pain threshold, and damage to these nociceptors activates the sympathetic nervous system to release neurotransmitters that cause reduced blood flow, which can further hinder the healing process. Joint instability due to capsular ligament injury could, therefore, negatively interfere with nociceptor firing patterns. Due to facet joint injury and cervical instability, the cervical spine vertebrae can easily become displaced or misaligned, which can cause impingement and pressure on the adjacent nerve roots and sympathetic trunk (Figures 2 and 3 ).

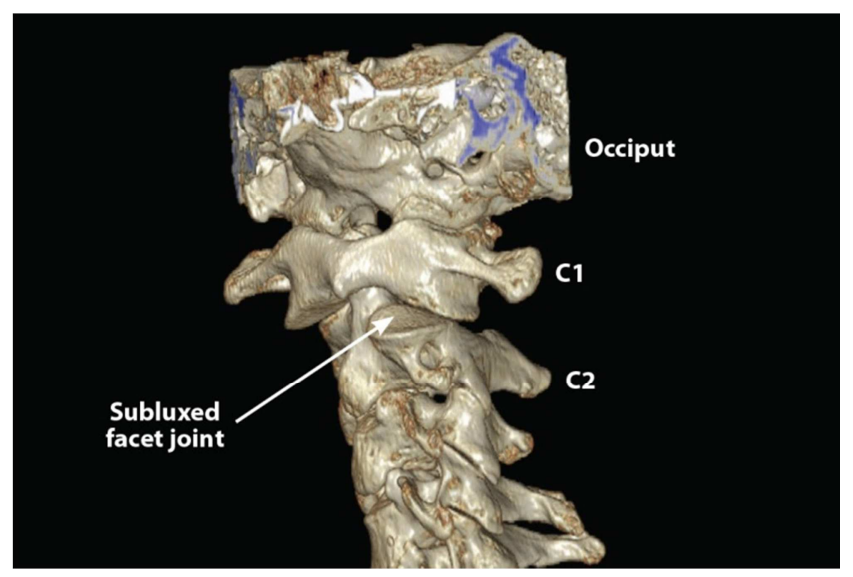

Figure 2. CT scan shows subluxation of the facet joint at C1-C2. Injury to the facet joint and capsular ligament laxity results in Barré-Liéou syndrome.

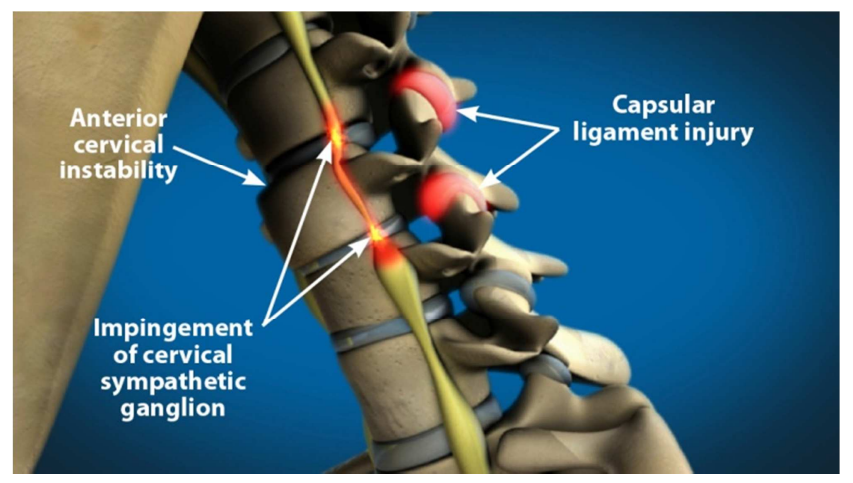

Figure 3. Capsular ligament laxity causes anterior cervical instability when the neck is flexed, resulting in impingement of the cervical sympathetic ganglion and producing symptoms of Barré-Liéou syndrome.

In a study of 318 patients with cervical spondylosis, $56 \%$ of those with sympathetic symptoms had radiographically-proven cervical spine instability [22]. Of these patients, the incidence of instability was much higher in women than men. The authors concluded, "Cervical spine instability is crucial in diagnosing sympathetic cervical spondylosis." In another study, 7 of 12 patients with cervical spondylosis and sympathetic symptoms were also diagnosed with cervical instability, as evident on radiographs and MRIs [23].

Instability in the neck has also been shown to be a potential factor for cervical vertigo [24]. Pathological changes to the cervical spine, including degeneration of both the discs and vertebrae, can cause sympathetic nerve irritation and lead to sympathetic symptoms, as shown in both human and animal studies [25-26].

The facet joints and capsular ligaments together provide significant stability in the neck, especially during axial rotation, and are essential components for ensuring neck 
stability with movement [27-30]. As the capsular ligaments lie close to the intervertebral centers of rotation, they play a critical role in stabilizing the spinal column and protecting the neural tissues from injury $[11,30]$. There is evidence that injury to the capsular ligaments is requisite for producing chronic pain and instability in the facet joint [11]. In simulations, whiplash trauma has also been shown to reduce cervical ligament strength (i.e., failure force and average energy absorption capacity) compared with controls or computational models. This is especially true in the case of capsular ligaments, in that it causes capsular ligament laxity [11]. Another study conclusively demonstrated that whiplash causes injury (i.e., increased laxity) to the capsular ligaments in the neck, in that elongation of the capsular ligaments after whiplash increased by $85 \%$ to $275 \%$ compared to control [31]. It is estimated that more than 740,000 whiplash injuries occur annually in the United States alone due to automotive incidents with many patients suffering from continued symptoms with a diagnosis of whiplash-associated disorder (WAD). These cervical spine injuries can result from side or back impacts in traumatic accidents causing extreme flexion and extension of the neck, which can lead to increased laxity in the capsular ligaments and then the potential for further complications.

\subsection{Overlapping Symptomatology of Barré-Liéou Syndrome, Whiplash Dysfunction, and Post-Concussion Syndrome}

The cervical spine contains multiple ligaments that help to connect the apophyseal (facet) and occipital-atlanto-axial joints. The transverse ligaments are important stabilizers to the joints. The occipital-atlanto-axial joint complex is partly stabilized by the alar ligaments, which consist of collagen fibers and can be stretched to about $10 \%$ of their original length until failure [33]. These ligaments are highly susceptible to strains, overstretching, and injury, which can cause headaches, neck pain, difficulty swallowing, radiculopathy, dizziness, tinnitus, and blurred vision when damaged [34]. These symptoms are consistent with Barré-Liéou syndrome, whiplash dysfunction, and post-concussion syndrome with some overlap of symptoms between the three conditions (Figure 1). It has been estimated that $30 \%$ of those patients who suffer a concussion will develop post-concussion syndrome, which has similar symptomatology with Barré-Liéou syndrome and whiplash dysfunction [35].

Neck pain and its associated symptoms may be related to a separate whiplash-type injury that occurred alongside the concussion [36]. Because of its added mobility, the upper cervical spine is particularly vulnerable to injury. Furthermore, at least one study indicates that in $75 \%$ of $\mathrm{C} 0-\mathrm{C} 2$ injuries, the rest of the cervical spine has also sustained injury as well [37]. Thus, it is quite plausible that trauma from a concussion could also cause damage to the cervical region of the spine, causing cervical instability and leading to symptoms such as those experienced in post-concussion syndrome $[11,36]$. One of the most common causes of cervical whiplash and neck disability is sprains and tearing of fibers in cervical ligaments [38].
Generalized headaches are usually caused by ligamentous or muscular injury to the head or neck region [39]. At least 1.7 million traumatic brain injuries (TBIs) occur annually [40]. According to the Sports Concussion Institute, $5 \%$ to $10 \%$ of athletes will experience a concussion in any given sports season, and about $53 \%$ of these athletes feel symptoms after a concussion blow [41]. These symptoms often include headache, neck pain, dizziness, and vertigo, which all overlap with Barré-Liéou syndrome. It may not be immediately clear whether someone has suffered a cervical spine injury since ligamentous injuries are often underdiagnosed as related to concussions. This instability of the cervical spine and its ligaments can compress vertebral blood vessels and the posterior cervical sympathetic chain. The decreased blood flow and the compression of nerves can cause symptoms of Barré-Liéou syndrome. Vertebrobasilar insufficiency, with symptoms of neck pain, headaches or migraines, dizziness, and auditory and visual disturbances, can also result from a whiplash-type trauma [42-45] (Figure 1). In addition to ligamentous injury, high-velocity chiropractic maneuvers can also result in vertebral artery injury or even dissection [46-47]. Changes in vertebral artery blood flow velocity have been shown upon normal neck rotation, with implications for vertebral artery blood flow upon trauma resulting in persistent occlusion [48-51].

Due to the overlap in symptomatology between these conditions, a common etiology such as underlying cervical instability should be considered. As such, we can postulate that Barré-Liéou syndrome may be more common in the general population and could be misdiagnosed as any of these other syndromes. It is important to understand that all of these syndromes have similar features: they often are diagnosed after neck trauma; symptoms often present themselves weeks to months after trauma; there is a lack of definitive diagnostic tests; and symptoms are often intermittent. For these reasons, an underlying cause of neck instability should be considered.

\subsection{Prolotherapy Treatment for Barré-Liéou Syndrome}

Barré-Liéou syndrome patients who present classic symptoms of the condition for treatment may often be provided temporaneous amelioration of their symptoms with medications designed for migraines, vertigo, or pain. These may include medications, such as Imitrex ${ }^{\circledR}$ (GSK, Philadelphia, $\mathrm{Pa}$ ) (sumatriptin succinate) to relieve the migraine or cluster headache pain, tricyclic antidepressants like amitriptyline for vertigo, selective serotonin reuptake inhibitors (SSRIs) for diffuse pain, Botox ${ }^{\circledR}$ (botulinum toxin) (Actavis, Parsippany, $\mathrm{NJ}$ ), or pain medications like oxycodone. However, these medications provide limited relief for specific episodes, and are not curative. In select patients, surgery with fusion may be offered, but the outcomes of this option may not be warranted in the risk-benefit analysis [8].

Comparatively, prolotherapy can provide immediate relief and gradual resolution of symptoms, while correcting the underlying malady leading to Barré-Liéou syndrome. Vertebral instability or malalignment, which occurs when neck ligaments become injured, affects the function of the nerve cell 
aggregations located anterior to the vertebrae. Prolotherapy re-strengthens the capsular ligaments and pulls the vertebrae of the cervical spine posteriorly into their normal position, thereby releasing pressure on the sympathetic nervous system.

The effect of prolotherapy on Barré-Liéou syndrome symptoms was first noted by Hemwall in the 1950s [52]. After Hemwall provided prolotherapy, his patients' neck pain and headache were relieved as was their corresponding dizziness, headaches, nausea, blurred vision, and tinnitus. A few patients even experienced improvements in their vision. Other serendipitous findings by Hemwall included improvement in paresthesias of the arms, generalized weakness, and ear, face, and tongue pain in his patients. Barré-Liéou syndrome patients also note an improvement in sinus congestion - particularly in those who had been dependent on sinus decongestant medication.

Prolotherapy has been used successfully for chronic whiplash-related neck pain. In a study of 98 patients, Hauser and Hauser reported that $98 \%$ of patients stated their neck pain was reduced with prolotherapy [53]. These study results are supported by an earlier study by Hackett and colleagues who reported $85 \%$ patient improvement in pain symptoms (including headache) after treating cervical ligaments with prolotherapy [38]. In a study by Centeno et al., six patients with a history of motor vehicle accident, subsequent neck pain, and radiographically-diagnosed cervical instability who received prolotherapy treatments to the neck experienced improved pain scores and decreased cervical spine translation, as confirmed with fluoroscopy [54]. In another series of 15 patients with chronic neck pain and history of whiplash (14 with history of motor vehicle accident), mean neck disability index scores were significantly reduced at 2, 6, and 12 months after dextrose prolotherapy injections to the facet joints [55].

In this case series, we document the results of pain and symptom amelioration following prolotherapy in patients with a diagnosis of Barré-Liéou syndrome.

\section{Patients and Procedures}

All of the patients whose case presentations are described in this report initiated prolotherapy injection therapy at Caring Medical and Rehabilitation, a chronic pain clinic, between August 2011 and September 2013. All of the patients were diagnosed with symptoms consistent with Barré-Liéou syndrome. Patient-centered treatment decisions were made on an individual basis. Every patient signed a consent form for treatment. If platelet-rich plasma or direct bone marrow aspirate was required, the patient signed an additional consent form for that procedure.

All patients' physical exams revealed loss of the normal cervical lordotic curve, crepitation, muscle tenderness in the trapezius, levator scapulae, and paraspinal muscles, and moderate-to-severe tenderness along the facet joints of the whole cervical spine, especially around $\mathrm{C} 0-\mathrm{C} 2$ and the suboccipital region. No patients had significant tenderness along the midline of the cervical spine. Range of motion was within normal limits except for Case 1, in whom lateral rotation was limited to 45 degrees bilaterally. Sensorimotor examinations were normal for upper extremities bilaterally. All patients presented with normal gait and station. All initial prolotherapy treatments following assessment of Barré-Liéou syndrome involved injection of $\mathrm{C} 1$ with subsequent injection of other affected cervical vertebrae based on need, which comprised the entire cervical spine (C1-C7) in some patients and the upper cervical spine $(\mathrm{C} 1-\mathrm{C} 4)$ in others. Prolotherapy injection to $\mathrm{C} 1$ was completed with a 2-inch, 25-gauge needle, and for all other treatments a 3-inch, 22-gauge needle was used. Prolotherapy injection sites are shown in Figures 4 and 5.

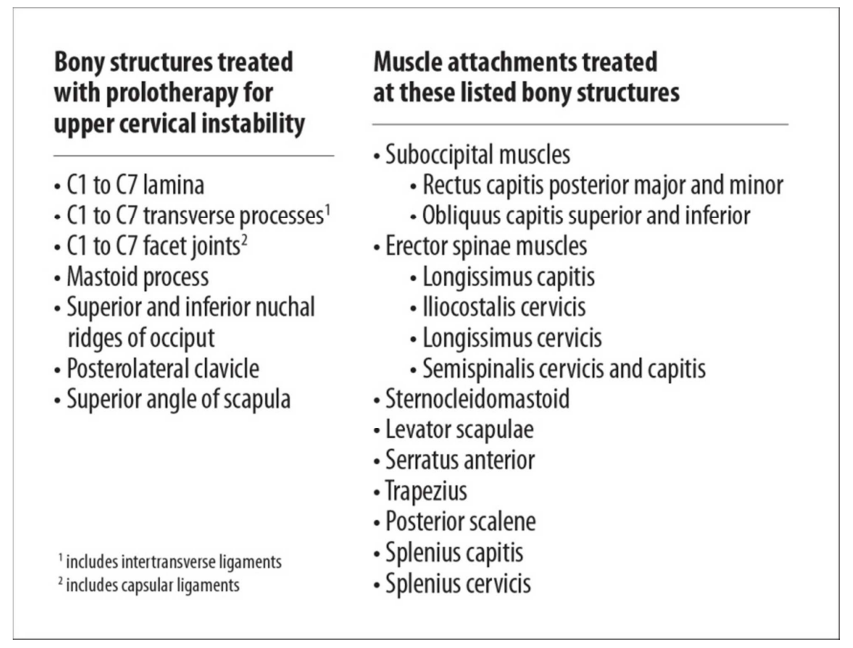

Figure 4. Prolotherapy injection sites for cervical instability are described.

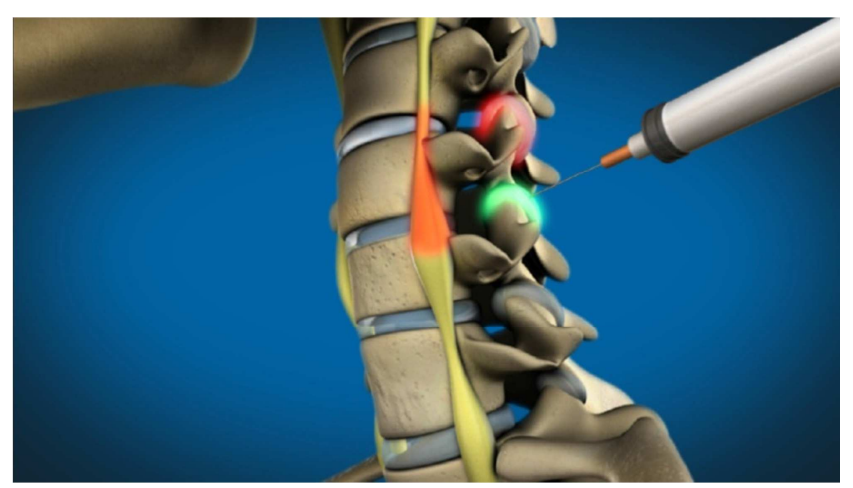

Figure 5. Prolotherapy injection sites to the mid-cervical region are illustrated.

Prolotherapy injection solution consisted of $15 \%$ dextrose, $0.1 \%$ procaine, and $10 \%$ sarapin with added sodium morrhuate or polidocanol as needed. Based on individual patient assessment, additional solvents included platelet-rich plasma (PRP) and direct tibial bone marrow.

\section{Case Presentations}

\subsection{Case 1}

E.O., a 33-year-old man from Ireland, presented to Caring Medical and Rehabilitation in September 2013 for an evaluation of his chronic neck pain and tinnitus that he suffered after a bicycle accident in 2008. The patient's neck 
pain was bilateral and constant, which prevented him from sleeping well. He admitted to taking tramadol and diazepam as needed for neck pain. In addition to the pain and tinnitus, the patient reported crepitation in his cervical spine and a history of vertigo and dizziness, but denied any radiculopathy. E.O. had previously tried chiropractic care (including manipulations) and physical therapy without relief.

E.O. received four prolotherapy treatments to his posterior neck over the next 5 months with gradual improvement of symptoms (Figure 6).

\begin{tabular}{|c|c|c|c|}
\hline Patient & Dates of Treatment & $\begin{array}{l}\text { Facet Joints (C0-C7) and } \\
\text { Ligaments Treated }\end{array}$ & Solutions and Additives \\
\hline \#1. (E.O.) & $\begin{array}{l}\text { 9/20/13, 10/25/13 } \\
12 / 6 / 13,1 / 10 / 14\end{array}$ & $\begin{array}{l}\text { C4-C7: Prolotherapy } \\
\text { C0-C3: PRP* }\end{array}$ & $\begin{array}{l}\text { Prolotherapy solutiont, } 55-75 \mathrm{cc} \\
\text { PRP } \\
\text { Polidocanol, } 0.5-1.0 \mathrm{cc}\end{array}$ \\
\hline \#2. (P.V.) & $\begin{array}{l}\text { 8/28/12, 10/30/12, 1/7/13, } \\
3 / 4 / 13,5 / 6 / 13\end{array}$ & $\mathrm{C} 1-\mathrm{C7}$ & $\begin{array}{l}\text { Prolotherapy solution, } 60-90 \text { cc } \\
\text { Polidocanol, } 1 \text { cc }\end{array}$ \\
\hline \#3 (N.N.) & $\begin{array}{l}\text { 8/6/12, 12/13/12, 6/3/13 } \\
7 / 25 / 13,9 / 30 / 13\end{array}$ & C1-C7 & $\begin{array}{l}\text { Prolotherapy solution, } 45-110 \mathrm{cc} \\
\text { Polidocanol } 1 \mathrm{cc}\end{array}$ \\
\hline \#4 (E.G.) & $\begin{array}{l}\text { 10/8/12, 11/9/12, } \\
\text { 12/12/12, } \\
\text { 1/11/13, 2/11/13, 3/24/13 }\end{array}$ & $\mathrm{C} 1-\mathrm{C} 7$ & $\begin{array}{l}\text { Prolotherapy solution, 60-77 cc } \\
\text { Polidocanol, .5 cc (Visits 1 \& 2) \& } \\
\text { Polidocanol, } 1 \text { cc (Visits 3-6) }\end{array}$ \\
\hline \#5 (C.H.) & $\begin{array}{l}4 / 13 / 12,9 / 8 / 12,10 / 12 / 12 \\
11 / 16 / 12,12 / 14 / 12\end{array}$ & $\begin{array}{l}\text { C1-C7 } \\
\text { (Visit 1: Right neck only } \\
\text { Visits 2-5: Left neck only) }\end{array}$ & $\begin{array}{l}\text { Prolotherapy solution, 40-66 cc } \\
\text { Polidocanol, } 1 \text { cc (Visits 2-5) }\end{array}$ \\
\hline \#6 (E.G.) & $\begin{array}{l}\text { 6/4/13, 7/11/13, 8/15/13 } \\
9 / 27 / 13,11 / 7 / 13,2 / 21 / 14\end{array}$ & $\begin{array}{l}\text { C1-C7 } \\
\text { (Visits 1-2 4-6) } \\
\text { C0-C3: PRP \& C4-C7: } \\
\text { Prolotherapy (Visit 3) } \\
\end{array}$ & $\begin{array}{l}\text { Prolotherapy solution, 60-11 cc } \\
\text { PRP }\end{array}$ \\
\hline \#7 (W.G.) & $\begin{array}{l}4 / 9 / 12,4 / 25 / 12,5 / 23 / 12 \\
6 / 20 / 12\end{array}$ & $\begin{array}{l}\text { C1-C7 (Visits 3-5 under } \\
\text { fluoroscopic guidance) }\end{array}$ & $\begin{array}{l}\text { X Prolotherapy solution, } 45-80 \mathrm{cc} \\
\text { Sodium morrhuate } .5 \mathrm{cc} \text { (Visits } \\
\text { 1-2) and } 1.0 \mathrm{cc} \text { (Visit 3) } \\
\text { Polidocanol, } 1 \text { cc (Visits 4-5) }\end{array}$ \\
\hline \#8 (D.K.) & $\begin{array}{l}\text { 8/31/11, 9/29/11 } \\
\text { 10/27/11, 12/5/11, } \\
\text { 1/12/12, 2/9/12, 3/14/12 } \\
4 / 2 / 12,4 / 25 / 12,5 / 23 / 12 \\
6 / 20 / 12,10 / 2 / 12,12 / 4 / 12\end{array}$ & $\begin{array}{l}\text { C1-C7, stylomandibular } \\
\text { ligaments } \\
\text { (Visits 7-11 under } \\
\text { fluoroscopic guidance) }\end{array}$ & $\begin{array}{l}\text { Prolotherapy solution, } 60-80 \mathrm{cc} \\
\text { Sodium morrhuate, } 0.5 \mathrm{cc} \text { (visits } \\
\text { 4-6) and } 1.0 \mathrm{cc} \text { (visits 7-8) } \\
\text { Polidocanol, } 1 \text { cc (visits 9-13) } \\
\text { PRP (visit 9-12) } \\
\text { Direct tibial bone marrow (visit 13) }\end{array}$ \\
\hline
\end{tabular}

Figure 6. Prolotherapy treatment protocol for Barré-Liéou syndrome case series patients at Caring Medical is described.

The patient was injected with 55-75 $\mathrm{cc}$ of solution at each visit, including PRP to the facet joints of $\mathrm{C} 1-\mathrm{C} 3$ bilaterally and with standard solution ( $15 \%$ dextrose, $0.1 \%$ procaine, and $10 \%$ sarapin) to the remaining areas (C4-C7). An additional 0.5 to $1.0 \mathrm{cc}$ of polidocanol was included in each syringe at each treatment. After two treatments, E.O. reported $40 \%$ improvement. The patient said that the crepitation in his neck had decreased significantly and his main complaint was no longer pain, just neck weakness. He no longer needed to take tramadol or diazepam for pain.

At his fourth and final visit, E.O. reported that his neck still felt weak, but neck crepitation was still reduced. E.O. said that he was continuing to avoid self-manipulation, which had become easier to refrain from. Since he still lived in Ireland,
E.O. became unable to travel to travel to the United States to continue treatment, but reported that he was maintaining improvement upon phone follow up in November 2014. At that time, E.O. said that he was continuing to improve in terms of pain and function in the hope that he could begin running again as a hobby.

\subsection{Case 2}

P.V., a 43-year-old male, came to our chronic pain clinic in August 2012 for treatment to his posterior neck. The patient had been in a motor vehicle accident 20 years ago. Eight months after the accident, he began to suffer from neck pain that had intensified over time. At the initial appointment, P.V. had burning pain that radiated from his neck down through his 
shoulders and arms to his fingers. These symptoms improved upon lying down, but increased when he stood up. When his neck pain was intense, P.V. experienced eye pain and cervical headaches. P.V. admitted that he self-manipulated his neck, which made him feel better temporarily. About a year prior to coming to our clinic, this patient had plain radiographs taken of his cervical spine, which showed disc degeneration at multiple levels. The orthopedic surgeon who ordered the radiographs did not think the discs were causing his pain, so P.V. was only managing his pain with occasional acetaminophen.

P.V. underwent a series of five prolotherapy treatments to his entire posterior cervical spine, including C1 (Figure 6). At each session, 60-90 cc of solution was administered throughout these locations. The solution consisted of $15 \%$ dextrose, $0.1 \%$ procaine, and $10 \%$ sarapin with the addition of $1 \mathrm{cc}$ polidocanol per $10 \mathrm{cc}$ syringe. The standard course for prolotherapy involves treatment every 4 to 6 weeks until symptoms are resolved, but P.V. received prolotherapy to his neck every 8 weeks due to his schedule. His last treatment was in March 2013.

With each treatment, P.V. noticed a decrease in his symptoms until his headaches, eye and facial pain, and radiculopathy were completely relieved. After his first treatment, the patient noticed a decrease in crepitation and radiculopathy symptoms. By his third treatment, his headaches and neck pain had reduced significantly. After his last appointment, P.V. reported substantial decreases in his pain and associated symptoms. During the time in between prolotherapy sessions, the patient wore a hard cervical collar during the day and a soft cervical collar at night. Since P.V. worked at a restaurant, it was imperative for him to wear a hard collar during the day to prevent excess rotation or flexion of his neck as he moved around the kitchen, as well as to prevent self-manipulation. As his symptoms continued to resolve, the patient was able to discontinue use of the collars. The patient's last follow up by phone was in March 2014, when P.V. reported his neck was doing well and pain remained resolved.

\subsection{Case 3}

N.N., a 57-year-old female, consulted Caring Medical and Rehabilitation for chronic neck pain and associated symptoms in August 2012. This patient suffered a motor vehicle accident at the age of 16 years old. Symptoms included severe headaches, jaw aches, neck and shoulder pain, brain fog, and eye pain. On average, her neck pain was 6 on a scale of 0 to 10 ( 0 meaning no pain and 10 being the worst pain possible) and frequency was 10 of 10 (100\% of the time). N.N. brought a recent $\mathrm{x}$-ray report to her first appointment that showed mild cervical degeneration without foraminal narrowing. The patient reported that she could feel her head "shift" when she did not wear a cervical collar.

N.N. was diagnosed with cervical instability and received four prolotherapy treatments at Caring Medical over an 11-month span to alleviate her pain and symptoms. Ideally, patients with this condition should receive treatment every 4 to 6 weeks. The patient's neck, including $\mathrm{C} 1$, was treated at every visit (Figure 6) with 45 to $110 \mathrm{cc}$ of solution, including $10 \%$ dextrose, $0.1 \%$ procaine, and $10 \%$ sarapin with an additional $1 \mathrm{cc}$ of polidocanol added to each $10 \mathrm{cc}$ syringe (maximum $10 \mathrm{cc}$ total). It was recommended that N.N. wear a hard cervical collar (Aspen ${ }^{\circledR}$ collar, Aspen Medical Products, Irvine, $\mathrm{CA}$ ) to prevent excessive motion of her cervical spine, especially $\mathrm{C} 1-\mathrm{C} 2$. Although the patient was not compliant with wearing a hard collar, she did wear a soft cervical collar which did help.

After her first treatment, N.N. reported a reduction in her headaches and pain, and stated that it felt as if her neck was becoming more stable. By her third visit, N.N. estimated she was about $80 \%$ better. At her fourth and final treatment in July 2013, N.N. could sleep on her side without her neck shifting and reported a 90\% improvement in all other symptoms. At the patient's last telephone follow up in March 2014, N.N. reported that she was doing well and had maintained her improvement.

\subsection{Case 4}

E.G., a 31-year-old female was first treated at our clinic in October 2012 for chronic neck pain of more than 10 years duration and associated suboccipital migraines. In 2001, E.G.'s job required her to do a lot of heavy lifting. It is thought that she injured her neck during that time, as that is when her neck pain began. At her initial visit, E.G. said that her pain was worse in the suboccipital area and she experienced significant crepitation upon neck movement. She admitted to self-manipulating her neck multiple times per hour as a way to temporarily relieve pain. Prior diagnostics of CT and x-ray showed the beginning stages of osteoarthritis. E.G. had tried chiropractic care, physical therapy, and medications to treat her chronic neck pain and migraines, but without relief.

E.G. underwent a series of six prolotherapy treatments to her complete cervical spine, including $\mathrm{C} 1$ (Figure 6). A total of 60-70 cc of solution was injected throughout these structures each time. Standard prolotherapy solution (15\% dextrose, $0.1 \%$ procaine, and $10 \%$ sarapin) was used with the addition of 0.5 cc polidocanol per syringe at the first and second visit, and 1.0 cc polidocanol per syringe on the third through sixth visits. (It is customary to increase this dosage if the patient does not appear to be improving at an expected rate.) Each treatment was spaced approximately 4 weeks from the previous one, with the exception of the patient's sixth session, which was 6 weeks after her fifth session. (The standard course of prolotherapy for cervical instability is treatment every 4 to 6 weeks.) After each treatment, E.G. slowly noticed a decrease of her symptoms. Throughout this time, she wore a soft cervical collar as needed for neck pain and what she described as "neck fatigue." The collar prevented her from self-manipulating her neck on a regular basis and minimally to moderately helped relieve her neck pain when it was really bothering her. At her fourth treatment, she reported that she was having more "good days" than "bad days" and the severity of her migraines had significantly decreased. By her sixth and final visit in March 2013, E.G. reported an $85 \%$ 
improvement with complete reduction in crepitation and migraine headaches. The patient was unavailable after this date for further follow up of long-term results.

\subsection{Case 5}

C.H., a 35-year-old male, was seen at Caring Medical and Rehabilitation for chronic neck pain following a motor vehicle accident in 2010. Along with neck pain, the patient began to experience associated symptoms of blurred vision, eye floaters, dizziness, and ear fullness on the left side. He also experienced migraines on a regular basis and reported that he had recurring crepitation in his neck with movement. C.H. was taking naproxen frequently for his migraine headaches. He had been seeing a chiropractor regularly for 8 months for high-velocity manipulations and self-manipulating his neck on his own for temporary relief. C.H. denied any numbness, tingling, or radiculopathy symptoms.

C.H. received five prolotherapy treatments between April 2012 and December 2012 for Barré-Liéou syndrome. The patient's right neck was only treated at the first visit while the left neck was treated every time (Figure 6). This was based on C.H.'s symptoms and pain location at each visit. An injection of 40-60 cc of solution was given at each treatment, consisting of $15 \%$ dextrose, $0.1 \%$ procaine, and $10 \%$ sarapin. It was recommended that the patient wear a hard cervical collar (Aspen ${ }^{\circledR}$ collar) 24 hours per day every day for 4 weeks after treatment, but the C.H. only wore it during the day and not while sleeping. For his last four treatment sessions, $1 \mathrm{cc}$ of polidocanol was added to each $10 \mathrm{cc}$ syringe to increase healing. Over this time, C.H. reported significant decreases in crepitation, blurry vision, migraines, and ear fullness. At his last visit in December 2012, the patient reported $90 \%$ overall improvement in his neck pain and associated symptoms since starting prolotherapy. Upon follow up in March 2014, the patient reported that he was no longer experiencing neck pain, no longer needed to wear a cervical collar, and could exercise without any restrictions.

\subsection{Case 6}

E.G., a 26-year-old female, came to our chronic pain clinic in June 2013 for prolotherapy treatment to her neck. Following a motor vehicle accident in 2011, E.G. was still suffering from chronic neck pain, dizziness, nausea, muscle spasms, and radiating pain into her shoulders. She had previously been diagnosed with whiplash injury and tried chiropractic care, physical therapy, and massage therapy-all without relief of her symptoms. The patient's MRI was normal except for some mild loss of the lordotic curve. Her digital motion x-ray (DMX) showed damage to multiple ligaments (posterior and anterior longitudinal ligaments, capsular ligaments, and the alar and accessory ligaments) and upper cervical instability. Due to E.G.'s chronic neck discomfort, she was taking tramadol $50 \mathrm{mg}$ every 4 to 6 hours daily for pain.

E.G. underwent a series of six prolotherapy treatments over the next 9 months. She was treated with a $15 \%$ dextrose, $0.1 \%$ procaine, and $10 \%$ sarapin solution with an additional $1 \mathrm{cc}$ of polidocanol per syringe. A total of 60-100 cc of solution was used at each treatment (Figure 6). In the time between her first and second treatment in June and July 2013, E.G. wore a soft cervical collar at least half of the time daily. After her first two treatments, the patient noticed that her headaches were decreasing in frequency and severity, but she was still struggling with the other symptoms. At her third visit in August, E.G. was also treated with PRP. This solution was targeted at $\mathrm{C} 0-\mathrm{C} 3$ facet joints bilaterally while the other treated areas received the previous solution. At her fourth visit in September, her nausea and dizziness had completely absolved. By her fifth visit in November 2013, E.G. reported $75 \%$ overall improvement and explained that she no longer needed to take tramadol every 4 to 6 hours. At that point, she reported only requiring 1.5 tablets per day. At her next appointment and treatment in February 2014, E.G. reported $75 \%$ overall improvement and reported that her headaches were continuing to decrease significantly.

\subsection{Case 7}

W.G., a 43-year-old male, presented to our clinic for prolotherapy treatment to his neck for chronic neck pain and daily migraines. The patient had a history of whiplash injury and multiple concussions that he suffered while playing football in high school and college. At the time, W.G.'s most recent MRI showed multiple bulging discs. He had previously tried National Upper Cervical Chiropractic Association (NUCCA) style of manipulation, a gentle and noninvasive technique to reduce $\mathrm{C} 1$ subluxation, but the chiropractor was unable to stabilize $\mathrm{C} 1$ and $\mathrm{C} 2$. The patient's DMX showed upper cervical instability and injury to multiple ligaments, including the posterior and anterior longitudinal ligaments, multiple capsular ligaments, and the accessory and alar ligaments. W.G. admitted to regular, daily self-manipulation of his cervical spine for temporary pain relief.

W.G. received five prolotherapy treatments between March 2012 and June 2012. The last three treatments were performed under fluoroscopic guidance (Figure 6) with 45-80 cc of total solution at each treatment session. (It should be noted that the standard course of prolotherapy treatments are typically administered 4 to 6 weeks apart, but in some patients they can be given at shorter intervals without harm to the patient.) The solution consisted of $15 \%$ dextrose, $0.1 \%$ procaine, and $10 \%$ sarapin. At his first and second treatments, an addition of 0.5 cc of sodium morrhuate was included in each $10 \mathrm{cc}$ syringe. At the patient's third visit, the amount of sodium morrhuate was increased to $1.0 \mathrm{cc}$ to stimulate more healing. At his fourth and fifth visit, $1.0 \mathrm{cc}$ of polidocanol was added to each syringe, as sodium morrhuate was no longer manufactured. With each treatment, W.G. noticed a continual decrease in neck pain, crepitation, and migraines. At his last follow up in April 2014, W.G. remained free of migraines and only occasionally suffered from subtle neck pain.

\subsection{Case 8}

D.K., a 53-year-old female, came to Caring Medical and 
Rehabilitation in 2011 for treatment of chronic neck pain that had lasted more than 35 years and underlying upper cervical instability. The patient said that her right side was more painful than her left. D.K. had been undergoing NUCCA chiropractic care for four months previous to her initial visit. At that time, her adjustments were not holding for more than a day, forcing her to get NUCCA three times per week. The patient denied any self-manipulation of her cervical spine. D.K. reported intermittent numbness and tingling in her wrists and upper extremities, neck stiffness, and crepitation. In addition, she suffered from dizziness and difficulty concentrating when her cervical vertebrae were out of alignment.

D.K. received 13 prolotherapy treatments from August 2011 to December 2012. It was recommended that she wear a soft cervical collar in between treatments to help her avoid extraneous rotation and movement of her neck. All 13 treatments involved injections to her neck and four of the sessions included treatments to her stylomandibular ligaments as well (Figure 6). D.K. received treatment with a variety of solutions, including standard solution (15\% dextrose, $0.1 \%$ procaine, and $10 \%$ sarapin) with additional sodium morrhuate or polidocanol, platelet-rich plasma, and direct tibial bone marrow. Throughout the duration of treatments, D.K. reported continual improvement with progressive relief of symptoms. While most of her treatments occurred in a private office setting, three treatment sessions (specifically visits 7, 8, and 9) were performed under fluoroscopic guidance and at a nearby chiropractic office.

By her seventh treatment in March 2012, D.K. was reporting 50\% improvement in her neck pain and associated symptoms. At that point, she was still experiencing crepitus and stiffness in her posterior neck. A DMX was performed to objectively evaluate the patient's cervical instability. Results revealed straightening of the normal lordosis, areas of anterolisthesis and retrolisthesis, damage to her posterior and anterior longitudinal ligaments, capsular ligaments, and alar and accessory ligaments, and abnormal lateral translation of C1 on C2. By her twelfth session in October 2012, D.K. reported $70 \%$ overall improvement. Upon her last telephone follow up in March 2014, D.K. no longer complained of pain, crepitation, or stiffness in her upper cervical vertebrae, including $\mathrm{C} 1$ and $\mathrm{C} 2$, and no longer needed to see a chiropractor for adjustments.

\section{Discussion}

In a study of 3,307 patients, Barré-Liéou syndrome had a reported incidence of $1.96 \%(n=64)$, with females more frequently affected (76.6\%) as compared with males (23.4\%) [56]. Whether an uncommon or misdiagnosed medical condition, Barré- Liéou syndrome produces chronic pain and a myriad of neurological-altering symptoms that are very real in patients who suffer from this disease. Patients who have presented to Caring Medical and Rehabilitation Patients for prolotherapy have generally suffered for years and have already visited their primary care physician or chiropractor for treatment without success.

As noted, indicative etiology of Barré-Liéou syndrome is neck trauma with associated sympathetic symptoms of neck pain, headaches, dizziness, and other cognitive and sensory disturbances of the head and neck related to cervical instability. Cervical spine instability occurs when the vertebrae of the cervical spine are not aligned, so the spine in that area is not fixed or constant. This instability indicates a pathological situation, which affects the normal structure compromising the integrity of neurological and arterial structures.

Diagnostic techniques, including DMX, MRI, and CT, assist in the diagnosis of Barré-Liéou syndrome after neck trauma [57-59], but are not the sole means for identification. In fact, diagnostics of upper cervical instability may be inconclusive because muscle spasm can prevent instability from being evident on imaging, as the muscles act as stabilizers [37]. This may be why Barré-Liéou syndrome is not commonly diagnosed, since there is no set criterion and no conclusive diagnostic test. Healthcare providers must suspect it and often rely only on symptoms and a physical examination for diagnosis. Anatomical hallmarks of the condition as well as clinical symptoms and range of motion are also used to diagnose Barré-Liéou syndrome.

Chronic pain relief and management can be challenging for the cervical spine. Various treatments options such as manipulation have shown to be risky. Manipulation involves high risk due to the proximity of the vertebral artery to the lateral cervical articulations. Manipulation is an extremely delicate task to perform because just one manipulation that is too forceful can lead to complications and even permanent damage [16-21]. On the other end of the spectrum, too many low-level manipulations can cause complications as well. Patients who chronically self-manipulate will most likely enhance their cervical instability because they are overstretching their joints allowing for greater joint laxity [14-15]. Overmanipulation syndrome includes symptoms of chronic pain and muscle spasms from ligament laxity due to manual therapy by a practitioner or by the patient himself.

Although surgery can be potentially successful, it generally does not come without risk and complications. In a 10-year study after occcipitocervical fusion, the atlas dens interval remained the same as immediately after surgery. The dislocation in the cervical spine returned to the preoperative condition [60]. Patients who have received a fusion for their cervical instability are actually at greater risk of neck trauma and further neck injury. Fused segments predispose adjacent vertebrae to the effects of future acute trauma and have shown to place the dens at risk of fracture due to concentrating extension forces at the $\mathrm{C} 1-\mathrm{C} 2$ articulation. Progressive deformity is another complication that can occur after laminectomy [61-64]. In another long-term study, 92\% of patients showed additional radiological degeneration of the adjacent disc levels after cervical interbody fusion surgery [65].

Prolotherapy treatment is a nonoperative, therapeutic injection of a dextrose-proliferating solution that is injected into tendons, ligaments, and joints. This treatment allows 
regeneration of new tissue at the site of the joint, ligament, or tendon [66-67] (Figure 7).

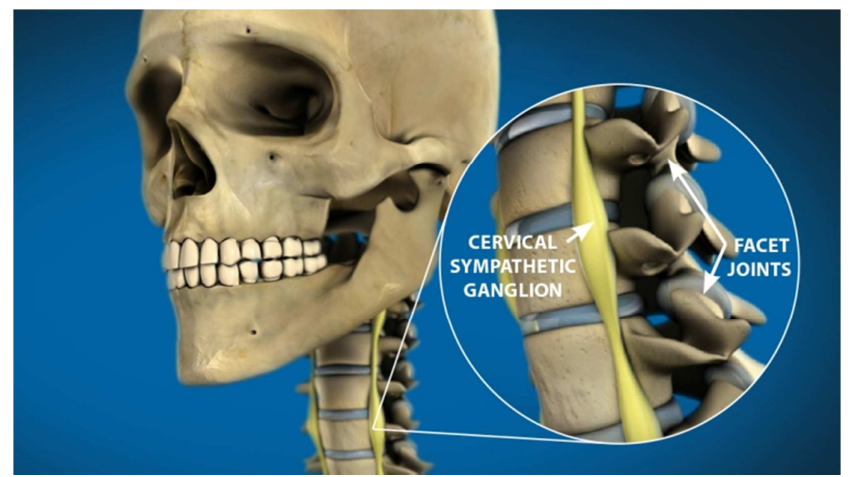

Figure 7. Cervical ligaments are repaired after prolotherapy. Joint instability and cervical sympathetic ganglion impingement are resolved, thus relieving associated symptoms of Barré-Liéou syndrome.

The patient returns for additional prolotherapy injections every few weeks until the patient is symptom free. As noted in this case series of eight patients, neck pain, migraines, and other symptoms were resolved following a prescribed series of prolotherapy injections administered in a pain clinic setting. These patients experienced complete or nearly complete amelioration of pain with relief that lasted months to years after prolotherapy treatment. The use of pain medication, chiropractics, and other therapy was no longer needed by the patients.

In prolotherapy, stimulation of the proliferation of new bone and fibrous tissue cells permanently strengthen the cervical region. Additionally, headaches managed by prolotherapy have shown to be successful in multiple studies. Some autonomic symptoms of the migraine are linked to the cervical region. In one study of 206 traumatic headache patients, $79 \%$ were completely relieved of their headaches from prolotherapy treatment [68]. Chronic neck pain and related symptoms of Barré-Liéou syndrome are also ameliorated with prolotherapy treatment as noted. Comprehensive prolotherapy can be effacious for $\mathrm{C} 1-\mathrm{C} 2$ instability.

Future study of a larger population of Barré-Liéou syndrome patients is needed to assess the average number of injections that are generally necessary in this patient population and to evaluate the long-term results. However, the results of this case series definitely show pain and symptom improvement in Barré-Liéou syndrome patients.

Prolotherapy is a regenerative injection technique (RIT) that provides a regenerative/reparative healing process through overlapping phases of inflammation, proliferation with granulation, and remodeling with contraction [11, 69]. Tensile strength, elasticity, mass, and load-bearing capacity of connective tissues are increased through prolotherapy [11, 69] and involve injection to both joints and ligaments. Hence, capsular ligaments, the stabilizing structures of the facet joints in the cervical spine, are strengthened through prolotherapy and symptoms of Barré-Liéou syndrome are resolved.

\section{References}

[1] Koleva I, Yoshinov R: Complex rehabilitation programme for amelioration of the quality of life of patients with Barre-Lieou syndrome. Ann Phys Rehab Med 2011, 54S: e107.

[2] Samy HM, Hamid MA, Friedman M, Egan RA, Manolidis S, Talavera F: Dizziness, vertigo, and imbalance. Medscape 2014 Oct 14. http://emedicine.medscape.com/article/2149881-overview.

[3] Smitherman TA, Burch R, Sheikh H, Loder E: The prevalence, impact, and treatment of migraine and severe headaches in the United States: a review of statistics from national surveillance studies. Headache 2013, 53(3): 427-436.

[4] Hain TC: Migraine associated vertigo. American Hearing Research Foundation 2012, October. http://american-hearing.org/disorders/migraine-associated-vert igo-mav/.

[5] Barré JA: [Sur un syndrome sympathique cervical posterieur et sa cause frequente: L'arthrite cervical]. Rev Neurol 1926, 33:1246-1248.

[6] Hauser RA, Hauser MA: Prolo Your Sports Injuries Away! Oak Park, IL: Beulah Land Press; 2001.

[7] Pearce J: Barré-Liéou “syndrome”. J Neurol Neurosurg Psychol 2004, 75(2): 319.

[8] Tamura T: Cranial symptoms after cervical injury. Aetiology and treatment of the Barré-Lieou syndrome. J Bone Joint Surg Br 1989, 71(2):283-287.

[9] Hauser RA, Hauser MA: Prolo Your Pain Away! (2 ${ }^{\text {nd }}$ ed.) Oak Park, IL: Beulah Land Press; 2004.

[10] Hauser RA, Hauser MA: Prolo Your Headache and Neck Pain Away! Oak Park, IL: Beulah Land Press, 2000.

[11] Steilen D, Hauser R, Woldin B, Sawyer S: Chronic neck pain: Making the connection between capsular ligament laxity and cervical instability. Open Ortho J 2014, 8:326-345.

[12] Liéou YC: [Syndrome sympathique cervical posterieur et arthrite cervicale chronique de la colonne vertébrale cervicale Etude clinique et radiologique These de Strasbourg], 1928.

[13] Boudin G, Barbizet, Pepin B, Fouet P: Syndrome grave da tronc cerebral apres manipulations cervicales [Severe syndrome of the brain stem caused by cervical manipulations]. Bull Mem Soc Med Hop Paris 1957, 73(18-19):562-566.

[14] Cook JW $4^{\text {th }}$, Sanstead JK: Wallenberg's syndrome following self-induced manipulation. Neurology 1991, 41(10):1695-1696.

[15] Rothrock JF, Hesselink JR. Teacher TM: Vertebral artery occlusion and stroke from cervical self-manipulation. Neurology 1991, 41(10):1696-1697.

[16] Ernst E: Adverse effects of spinal manipulation: a systematic review. J R Soc Med 2007, 100(7): 330-338.

[17] Ernst E: Deaths after chiropractic: a review of published cases. Int J Clin Pract 2010, 4(8):1162-1165.

[18] Ernst E: Vascular accidents after neck manipulation: cause or coincidence? Int J Clin Pract 2010, 64(6):673-677. 
[19] Leon-Sanchez A, Cuetter A, Ferrer G: Cervical spine manipulation: an alternative medical procedure with potentially fatal complications. South Med J 2007, 100(2):201-203.

[20] Haldeman S, Kohlbeck FJ, McGregor M: Unpredictability of cerebrovascular ischemia associated with cervical spine manipulation therapy: a review of sixty-four cases after cervical spine manipulation. Spine (Phila Pa 1976) 2002, 27(1):49-55.

[21] Di Fabio RP: Manipulation of the cervical spine: risks and benefits. Phys Ther 1999, 79(1):50-65.

[22] Qian J, Tian Y, Qiu GX, Hu JH: Dynamic radiographic analysis of sympathetic cervical spondylosis instability. Chin Med Sci J 2009, 24:46-49.

[23] Li C, Liu X, Ma Z, Yi X: [The effect of cervical spine instability on sympathetic cervical spondylosis]. Zhonghua Wai Ke Za Zhi 2002, 40(10):730-732.

[24] Wang Z, Wang X, Yuan W, Jiang D: Degenerative pathological irritations to cervical PLL may play a role in presenting sympathetic symptoms. Med Hypotheses 2011, 77(5):921-923.

[25] Li J, Gu T, Yang H, Liang L, Jiang DJ, Wang ZC, Yuan W, Wang XW: Sympathetic nerve innervation in cervical posterior longitudinal ligament as a potential causative factor in cervical spondylosis with sympathetic symptoms and preliminary evidence. Med Hypotheses 2014, 82(5):631-635.

[26] Wang XW, Gu T, Yuan W: [Treatment and mechanism of cervical spondylosis with sympathetic symptoms]. Zhonghua Wai Ke Za Zhi 2008, 46(18):1424-1427.

[27] Quinn KP, Lee KE, Ahaghotu CC, Winkelstein BA: Structural changes in the cervical facet capsular ligament: potential contributions to pain following subfailure loading. Stapp Car Crash J 2007, 51:169-187.

[28] Panjabi MM, Nibu K, Cholewicki J: Whiplash injuries and the potential for mechanical instability. Eur Spine J 1998, $7(6): 484-492$

[29] Zdeblick TA, Abitbol JJ, Kunz DN, McCabe RP, Garfin S: Cervical stability after sequential capsule resection. Spine (Phila, Pa 1976) 1993, 18(4):2005-2008.

[30] Rasoulinejad P, McLachlin SD, Bailey SI, Gurr KR, Bailey CS, Dunning CE: The importance of the posterior osteoligamentous complex to subaxial cervical spine stability in relation to a unilateral facet injury. Spine J 2012, 12(7):590-595.

[31] Ivancic PC, Coe MP, Ndu AB, Tominaga Y, Carlson EJ, Rubin W, Dipl-Ing FH, Panjabi MM: Dynamic mechanical properties of intact human cervical spine ligaments. Spine J 2007, $7(6): 659-665$

[32] Kleinberger M, Sun E, Saunders J, Zhou Zaifei: Effects of Head Restraint Position on Neck Injury in Rear Impact. National Highway Traffic and Safety Administration, Washington, D.C., 2010.

[33] Panjabi M, Dvorak J, Crisco III JJ, Oda T, Wang P, Grob D: Effects of alar ligament transection upon cervical spine rotation. J Orthop Res 1991, 9(4):584-593.

[34] Hohl M: Soft tissue injuries of the neck. Clin Orthop Relat Res 1975, 109:42-49.

[35] Leddy J, Sandhu H, Sodhi V, Baker J, Willer B: Rehabilitation of concussion and post-concussion syndrome. Sports Health 2012, 4(2):147-154.

[36] Barkhoudarian G, Hovda DA, Giza CC: The molecular pathophysiology of concussive brain injury. Clin Sports Med 2011, 30(1):33-48.

[37] Swinkels RA, Oostendorp RA: Upper cervical instability: fact or fiction? J Manipul Physiol Therap 1996,19(3):185-194.

[38] Hackett GS: Prolotherapy in whiplash and low back pain. Postgrad Med 1960, 27:214-219.

[39] Havsy SL: Whiplash injuries of the cervical spine and their clinical sequelae Part II. Am J Prev Med 1994, 4(2):73-82.

[40] Center for Disease Control and Prevention: Injury Prevention and Control: Traumatic Brain Injury. Atlanta, GA: Center for Disease Control and Prevention; 2013. http://www.cdc.gov/traumaticbraininjury/statistics.html.

[41] Sports Concussion Institute: Concussion Facts. Los Angeles, CA: Sport Concussion Institute; 2012. http://www.concussiontreatment.com/concussionfacts.html.

[42] Kuether TA, Nesbit GM, Clark VM, Barnwell SL: Rotational vertebral artery occlusion: a mechanism of vertebrobasilar insufficiency. Neurosurgery 1997, 41(2):427-432.

[43] Yang PJ, Latack JT, Gabrielsen TO, Knake JE, Begarski SS, Chandler WF: Rotational vertebral artery occlusion at C1-C2. AJNR Am J Neuroradiol 1985, 6(1):96-100.

[44] Endo K, Ichimaru K, Komatagata M, Yamamoto K: Cervical vertigo and dizziness after whiplash injury. Eur Spine J 2006, 15(6):886-890.

[45] Creighton D, Kondratek, M, Krauss J, Huijbregts P, Qu H: Ultrasound analysis of the vertebral artery during non-thrust cervical translatoric spinal manipulation. J Man Manip Ther 2011, 19(2):84-90.

[46] Parenti G, Orlandi G, Bianchi M, Renna M, Martini A, Murri L: Vertebral and carotid artery dissection following chiropractic cervical manipulation. Neurosurg Rev 1999, 22(2-3):127-129.

[47] Mehalic T, Farhat SM: Vertebral artery injury from chiropractic manipulation of the neck. Surg Neurol 1974, 2(2):125-129.

[48] Mitchell JA: Changes in vertebral artery blood flow following normal rotation of the cervical spine. J Manip Physiol Ther 2003, 26(6):347-351.

[49] Mitchell J: Vertebral artery blood flow velocity changes associated with cervical spine rotation: a meta-analysis of the evidence with implications for professional practice. J Man Manip Physiol Ther 2009, 17(1):46-57.

[50] Haynes M, Hart R, McGeachie J: Vertebral arteries and neck rotation: Doppler velocimeter interexaminer reliability. Ultrasound Med Biol 2000, 26(8):57-62.

[51] Kleynhans AM: The prevention of complications from spinal manipulative therapy. In: Idezk RM, ed. Aspects of manipulative therapy. Proceedings of the Lincoln Institute of Health Sciences Conference. Melbourne, 1980, 133-141.

[52] Hauser RA: Barré-Liéou syndrome. Get Prolo.com. http://www.getprolo.com/barre-lieou-syndrome/.

[53] Hauser RA, Hauser MA: Dextrose prolotherapy for unresolved neck pain. Practical Pain Management 2007, 7(8):56-69. 
[54] Centeno CJ, Elliott J, Elkins WL, Freeman M: Fluoroscopically guided cervical prolotherapy for instability with blinded pre and post radiographic reading. Pain Physician 2005, $8(1): 67-72$.

[55] Hooper RA, Frizzell JB, Faris P: Case series on chronic whiplash related neck pain treated with intraarticular zygaphophyseal joint regeneration injection therapy. Pain Physician 2007, 10(2):313-318.

[56] Rotes-Querol J, Crespi PB, Puiggros AC: [Studies on syndromes of the locomotor apparatus of psychic origin. The Barre-Lieou syndrome]. Rev Rhum Mal Osteoartic 1960, 27: 206-213.

[57] Johansson BH: Whiplash injuries can be visible by functional magnetic resonance imaging. Pain Res Manage 2006, 11(3): 197-199.

[58] Jónsson H Jr, Bring G, Rauschning W, Sahlstedt B: Hidden cervical spine injuries in traffic accident victims with skull fractures. J Spinal Disord 1994, 4(3): 251-263.

[59] Kaale BR, Krakenes J, Albrektsen G, Wester K: Head position and impact direction in whiplash injuries: associations with MRI-verified lesions of ligaments and membranes in the upper cervical spine. J Neurotrauma 2005, 22(11): 1294-1302.

[60] Matsunaga S, Ijiri K, Koga H: Results of a longer than 10-year follow-up of patients with rheumatoid arthritis treated by occipitocervical fusion. Spine (Phila, $\mathrm{Pa}$ 1976) 2000, 25(14):1749-1753.

[61] Ryken TC, Heary RF, Matz PG, Anderson PA, Groff MW, Holly LT, Kaiser MG, Mummaneni PV, Choudhri TF, Vresilovic EJ, Resnick DK, Joint Section on Disorders of the Spine and Peripheral Nerves of the American Association of Neurological Surgeons and congress of Neurological Surgeons: Cervical laminectomy for the treatment of cervical degenerative myelopathy. J Neurosurg Spine 2009, 11(2):142-149.
[62] Della Pepa GM, Roselli R, La Rocca G, Spallone A, Barbagallo $\mathrm{G}$, Visocchi M: Laminoplasty is better of laminectomy in cervical stenotic myelopathy: myth or truth? Eur Rev Med Pharmacol Sci 2014, 18(1 Suppl):50-54.

[63] Panchal RR, Duong HT, Shahlaie K, Kim KD: Cervical spinous process reconstruction. J Neurosurg Spine 2014, 20(1):18-21.

[64] Si Y, Wang Z, Yu T, Lin GZ, Zhang J, Zhang K, Zhang H, Li YC: Results of cervical recapping laminoplasty: gross anatomical changes, biomechanical evaluation at different time points and degrees of level involvement. PloS One 2014, 9(6): e100689.

[65] Goffin J, Geusens E. Vantomme N, Quintens E, Waerzeggers Y, Depreitere B, Van Calenbergh F, van Loon J. Long-term follow-up after interbody fusion of the cervical spine. J Spinal Disord Tech 2004, 17(2):79-85.

[66] Hauser RA, Sprague IS: Outcomes of prolotherapy in chondromalacia patella patients: improvements in pain and function. Clin Med Insights Arthritis Musculoskelet Disord 2014, 7:13-20.

[67] Fullerton BD: High-resolution ultrasound and magnetic resonance imaging to document tissue repair after prolotherapy: a report of 3 cases. Arch Phys Med Rehabil 2008, 89(2):377-385.

[68] Kayfetz DO, Blumenthal LS, Hackett GS, Hemwall GA, Neff FE: Whiplash injury and other ligamentous headache-its management with prolotherapy. Headache 1963, 3(1):21-28.

[69] Linetsky FS, Mikulinsky A, Gorfine L: Regenerative injection therapy: history of applications in pain management part I 1930s-1950s. Pain Clin 2000, 2:8-13. 